\title{
What surgical approach would provide better outcomes in children and adolescents undergoing cholecystectomy? Results of a systematic review and meta- analysis
}

Daniel Steffens $s^{1,2^{*}}$ D, Kathryn Wales ${ }^{1,2}$, Clare Toms ${ }^{1,2}$, David Yeo ${ }^{1,2,3,4}$, Charbel Sandroussi ${ }^{1,2,3,4}$ and Ashish Jiwane ${ }^{5}$

\begin{abstract}
Background: There is a lack of evidence on the surgical approach for children and adolescents undergoing cholecystectomy. Therefore, the aim of this systematic review is to compare the safety and efficacy of minimally invasive cholecystectomy to open cholecystectomy in children and/or adolescents.

Main body: A search was conducted on MEDLINE, PubMed, Cochrane and Embase from inception to October 2018. We included comparative studies investigating outcomes following robotic-assisted, laparoscopic and/or open cholecystectomy in children and/or adolescents. The outcomes of interest included post-operative complication rate, operation time, length of hospital stay, post-operative pain and conversion to open procedure. The NewcastleOttawa Scale was used to assess the risk of bias. Meta-analysis was performed using random-effect models. Twenty-one studies were included involving 927 children and/or adolescents. All, but one, compared outcomes between laparoscopic versus open cholecystectomy. The great majority of the included studies presented a low risk of bias. Patients undergoing laparoscopic cholecystectomy had less post-operative complications (RR: 0.57; 95\% Cl 0.35 to 0.94$)$, reduced length of hospital stay $(\mathrm{MD}-3.73 ; 95 \% \mathrm{Cl}-4.88$ to -2.59$)$, but longer operative time (MD $26.61 ; 95 \% \mathrm{Cl} 9.35$ to 43.86 ) when compared to open cholecystectomy. The average conversion from laparoscopic to open cholecystectomy was $7 \%$ across studies.

Conclusions: The current evidence suggested that laparoscopic cholecystectomy in children and/or adolescents is safe resulting in lower rates of postoperative complications and length of stay, but longer operative times, when compared to the open approach.
\end{abstract}

PROSPERO registration: CRD42017067641

Level of evidence: Level III

Keywords: Cholecystectomy, Children, Minimally invasive surgery, Systematic review, Outcomes

\footnotetext{
* Correspondence: daniel.steffens@health.nsw.gov.au

'Surgical Outcomes Research Centre (SOuRCe), PO Box M157 Missenden

Road, Sydney, New South Wales 2050, Australia

${ }^{2}$ Faculty of Medicine and Health, The University of Sydney, Central Clinical

School, Sydney, New South Wales, Australia

Full list of author information is available at the end of the article
}

\section{SpringerOpen}

(c) The Author(s). 2020 Open Access This article is licensed under a Creative Commons Attribution 4.0 International License, which permits use, sharing, adaptation, distribution and reproduction in any medium or format, as long as you give appropriate credit to the original author(s) and the source, provide a link to the Creative Commons licence, and indicate if changes were made. The images or other third party material in this article are included in the article's Creative Commons licence, unless indicated otherwise in a credit line to the material. If material is not included in the article's Creative Commons licence and your intended use is not permitted by statutory regulation or exceeds the permitted use, you will need to obtain permission directly from the copyright holder. To view a copy of this licence, visit http://creativecommons.org/licenses/by/4.0/. 


\section{Background}

Gallstone disease (cholelithiasis/choledocolithiasis/biliary colic) is relatively uncommon in paediatric patients, but when present is often attributed to haemolytic disease or prematurity [1]. Acute cholecystitis can also be acalculous in nature, stimulated by a recent viral illness or by chronic disease [2]. Rising childhood obesity has dramatically increased the incidence of paediatric gallstone disease globally [1]. The management of acute cholecystitis or biliary colic is often by surgical removal of the gallbladder (cholecystectomy) either through an open or laparoscopic approach. Minimally invasive surgery has become the standard approach for most thoracic, abdominal and pelvic procedures in adults and children [3]. Consequently, cholecystectomy for gallstone disease or biliary dyskinesia is being performed with rising frequency in children and has evolved from open to a minimally invasive approach [4].

Some of the main advantages of minimally invasive surgery, when compared to open surgery, is reduced postoperative pain, improved cosmesis and quicker recovery [3]. These advantages are particularly important in paediatric patients in whom scars enlarge with growth and the advantages of minimal incisions are more obvious [4]. For this reason, a rapid shift towards laparoscopic cholecystectomies occurred despite a lack of high-quality randomised trials, investigating the effectiveness of minimally invasive surgery over conventional open surgery [4].

In the adult population, there is some evidence suggesting that patients undergoing a laparoscopic cholecystectomy have equivalent mortality rates, postoperative complications and operation times when compared to open cholecystectomy [5]. Similarly, no difference in outcomes was found in a systematic review investigating the effectiveness of robotic versus laparoscopic cholecystectomy in adults [6]. Interestingly, in the elderly population, the laparoscopic approach provides better morbidity and mortality outcomes when compared to open cholecystectomy [7].

Currently, no study has systematically reviewed the literature to investigate the safety and effectiveness of minimally invasive cholecystectomy compared to open surgery in the paediatric population. Therefore, the aim of this systematic review and meta-analysis is to compare the safety and efficacy of minimally invasive (robotic-assisted or laparoscopic) cholecystectomy to open cholecystectomy in children and adolescents.

\section{Main text}

\section{Protocol and registration}

The protocol of this systematic review was written in accordance with the Preferred Reporting Items for Systematic Review and Meta-Analysis Protocols (PRISMA-P) [8] and registered a priori in the International Prospective Register of Systematic Reviews (PROSPERO 2017
CRD42017067641), available from https://www.crd.york. ac.uk/prospero/display_record.php?RecordID=67641.

\section{Inclusion criteria}

This review included comparative studies (e.g. randomised controlled trials [RCTs], cohort studies) reporting the safety and efficacy of minimally invasive (robotic or laparoscopic) compared to open procedures (cholecystectomies). Eligible studies met the following criteria: (i) reported on children and adolescents ( $\leq 18$ years old) of any gender; (ii) performed a cholecystectomy; and (iii) reported at least one outcome measure including complication rate, operation time, length of hospital stay, pain and conversion to open procedure. No language or publication restrictions were employed, with translations attempted for all non-English published studies. Case series reporting on a sample $<5$ and abstracts published in conference proceedings were excluded.

\section{Search strategy}

A comprehensive electronic search of MEDLINE, EMBASE, the Cochrane Central Register of Controlled Trials (CENTRAL) (via OVID) and PubMed (www.ncbi. nlm.nih.gov/pubmed) databases was conducted from their earliest records to October 2018. Recommendations from the Cochrane Handbook for Systematic Reviews of Interventions (http://handbook.cochrane.org/ chapter_6/6_4_2_structure_of_a_search_strategy.htm) were used to develop the search strategy. Combined terms, medical subject headings and keywords were used to create a highly sensitive search strategy in order to identify potential studies. Additional citation tracking of the included studies was also conducted.

\section{Data extraction process}

Initially, one reviewer (KW) screened each citation by title and abstract to identify potentially eligible studies for inclusion. Any studies whereby the eligibility remained unclear were included as a potentially eligible study. The full text for each potentially eligible article was obtained and assessed by two independent reviewers (CT, KW or DS) to determine whether the study inclusion criteria had been met. Any disagreements between the two reviewers were resolved by discussion. For all excluded full-text articles, the main reason for exclusion was identified. Two independent review authors (CT, DS and KW) extracted data from the included studies using a pre-constructed data extraction form, which was initially tested for comprehensiveness and ease. Study information, participant baseline characteristics, intervention, control and outcome data were extracted and collated. Where more than one publication for a study was found, data was extracted from the most comprehensive publication. Discrepancies in data 
extracted by the reviewers were resolved by discussion with a senior review author (DY, AJ or CS).

\section{Risk of bias assessment}

The risk of bias in included studies was assessed by two independent review authors (CT, KW or DS). Disagreements were resolved by discussion with a senior review author (DY, AJ or CS). The methodological quality of the included studies was appraised by the NewcastleOttawa Scale (NOS). The NOS tool consists of a checklist of eight items specifically designed for non-RCTs reporting on the selection (4 items), comparability ( 1 item) and outcome (3 items). Methodological quality was not regarded as an inclusion criterion.

\section{Statistical analysis}

Meta-analyses were performed with data being pooled using random effects models. Dichotomous data were expressed as relative risks and $95 \%$ confidence intervals, while continuous data were expressed as mean differences and 95\% confidence intervals. Forest plots were utilized to visualize the data, and the statistical heterogeneity of the included studies was assessed using the $I^{2}$ test. Comprehensive Meta-Analysis (CMA) software was used for all analyses. Patient information, risk of bias, types of complications and conversion of procedures are presented descriptively.

\section{Results}

\section{Selection of studies}

The initial search on four medical databases identified 3912 articles after duplicates were removed. Of these, 376 full-text articles were reviewed for eligibility, with 23 of these meeting the eligibility criteria and included in this review. Most of the full-text articles were excluded due to reporting on a sample $>18$ years old $(n=199)$ or not having a comparison group $(n=120)$. The complete flow diagram of included articles can be found in Fig. 1 . Of the 23 included studies, 4 presented data from two different cohorts [9-12]; therefore, this review synthesises the results of 21 unique studies.

\section{Risk of bias assessment}

The risk of bias assessment for all included studies is described in full detail in Table 1. Of all the included studies, only one presented a high risk of bias in the

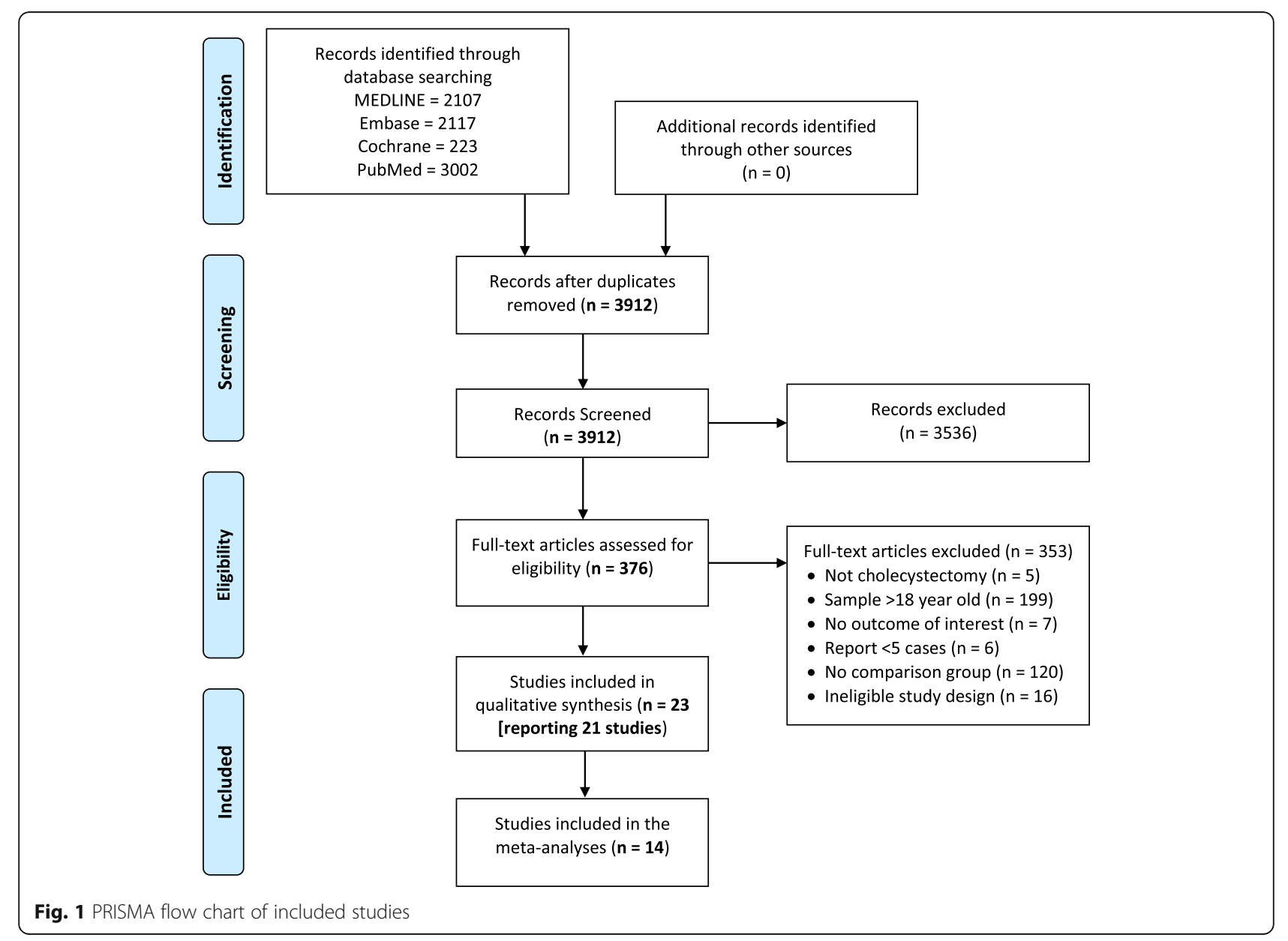




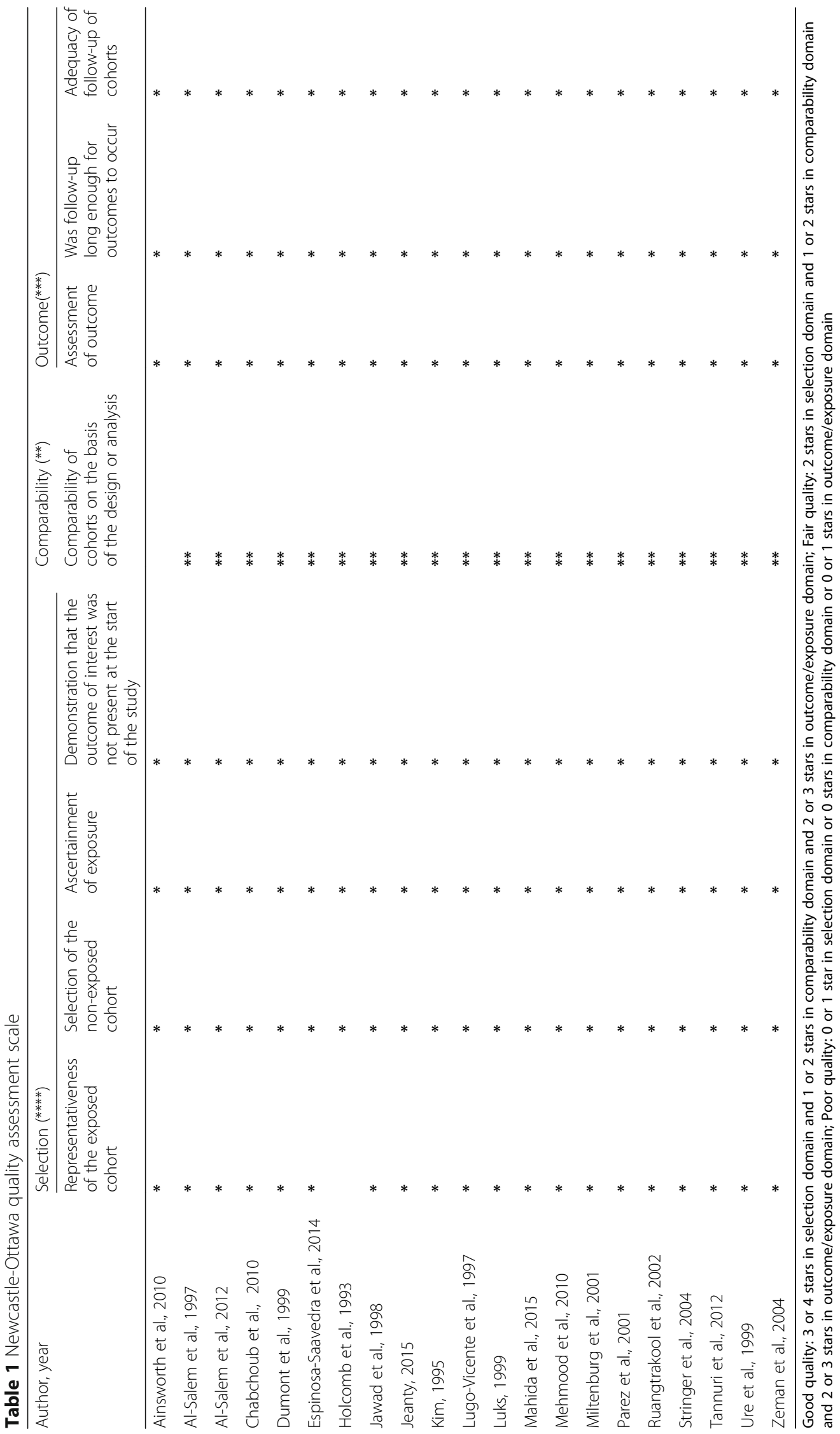


comparability domain [13] and one on the selection [14] (i.e. representativeness of the exposed cohort). Overall, most studies presented a low risk of bias.

\section{Characteristics of included studies}

A total of 927 unique children and/or adolescents were reported on the included 21 articles $[9,10,13-31]$ with the majority of the included studies comparing outcomes between laparoscopic versus open cholecystectomy (20/21). A single study compared outcomes of robotic cholecystectomy and laparoscopic cholecystectomy [23]. The study sample sizes ranged from 10 [19] to 221 [29] patients with the mean age ranging from 0.4 [19] to 14.8 [21] years, with a female predominance (Table 2).

\section{Laparoscopic versus open cholecystectomy Post-operative in-hospital complication rate}

A total of 16 studies investigated post-operative inhospital complications following laparoscopic or open cholecystectomy. Of these, 7 studies reported no postoperative complication following laparoscopic $(n=125)$ or open cholecystectomy $(n=43)[13,14,16,18,19,24$, $28]$. The pooled results of 7 studies $(n=523)[9,10,21$, 25-27, 29] demonstrated that patients undergoing laparoscopic cholecystectomy were less likely to develop postoperative complications when compared to patients who underwent open cholecystectomy (RR: 0.57; 95\%CI: 0.35 to 0.94 ) (Fig. 2). Two of the included studies $(n=$ 43) $[15,17]$ reported one postoperative complication each (i.e. wall infection and lung infection), although they have not assigned this to any procedure (e.g. laparoscopic or open cholecystectomy).

\section{Operative time}

Operative time was investigated in 9 studies. The pooled operative time of 7 studies $(n=299)[9,10,18,20,22$, $25,30]$ demonstrated that open cholecystectomy had a significantly lower duration when compared with laparoscopic cholecystectomy (MD: $26.61 \mathrm{~min} ; 95 \% \mathrm{CI} 9.35$ to 43.86) (Fig. 3).

Holcomb et al. [14] reported that the mean operative time was $110 \mathrm{~min}$ for open cholecystectomy and $106 \mathrm{~min}$ for the laparoscopic procedure ( $p$ value not reported), whereas Lugo-Vicente et al. [21] reported a significant shorter operative time for laparoscopic cholecystectomy when compared to open cholecystectomy (94 versus 138 min, respectively; $p=0.03$ ).

\section{Length of hospital stay}

All 17 studies that investigated the length of hospital stay demonstrated that patients that underwent laparoscopic surgery have a shorter stay when compared to open cholecystectomy patients $[9,10,13,14,16-18,20-$
22, 25-31]. Our meta-analysis including 574 patients showed that children who underwent open cholecystectomy stayed approximately 4 days longer than children who underwent laparoscopic cholecystectomy (MD 3.73 days; $95 \% \mathrm{CI}-4.88$ to -2.59 ) (Fig. 4 ) $[9,10,13,17$, $18,20,22,27-30]$.

\section{Post-operative pain}

Only two studies investigated postoperative pain outcomes following laparoscopic and open cholecystectomy [21, 25]. Lugo-Vicente et al. [21] reported the number of days patients required pain medication. Patients undergoing laparoscopic cholecystectomy had a significantly shorter duration for requiring pain medication than the open cholecystectomy group ( 0.7 versus 1.4 days respectively, $p<0.001$ ). Milternburg et al. [25] reported that patients that underwent open cholecystectomy required more postoperative analgesia compared with patients who underwent laparoscopic cholecystectomy (morphine $0.7 \mathrm{mg} / \mathrm{kg}$ versus $1.5 \mathrm{mg} / \mathrm{kg}$ ), although the difference between groups was not significant.

\section{Conversion to open cholecystectomy}

Twelve studies report on conversion rates from laparoscopic to open cholecystectomy $(n=479)[9,10,13,19$ $21,25-29,31]$. Conversion rates ranged from $0 \%[20$, 28 ] to $25 \%$ [19], whereas the average across all studies was $7 \%$.

\section{Robotic cholecystectomy versus laparoscopic cholecystectomy}

One study compared robotic $(n=46)$ versus laparoscopic cholecystectomy ( $n=$ not reported) [23]. No outcomes were reported for post-operative complication rates, operative time, post-operative pain and conversion rates. The median length of hospital stay between patients that underwent robotic or laparoscopic cholecystectomy was equivalent (1 versus 1 day, respectively; $p=0.92)$.

\section{Conclusions}

\section{Statement of principal findings}

This systematic review and meta-analysis identified 21 unique comparative studies reporting on 927 children and/or adolescents that underwent a cholecystectomy. Twenty studies compared outcomes following laparoscopic and open cholecystectomies, and only one study compared robotic-assisted with laparoscopic cholecystectomy. No randomised controlled trial or studies comparing robotic-assisted versus open cholecystectomy was identified.

The results of this systematic review and meta-analysis indicate that children and/or adolescents undergoing a laparoscopic cholecystectomy had a lower post-operative 


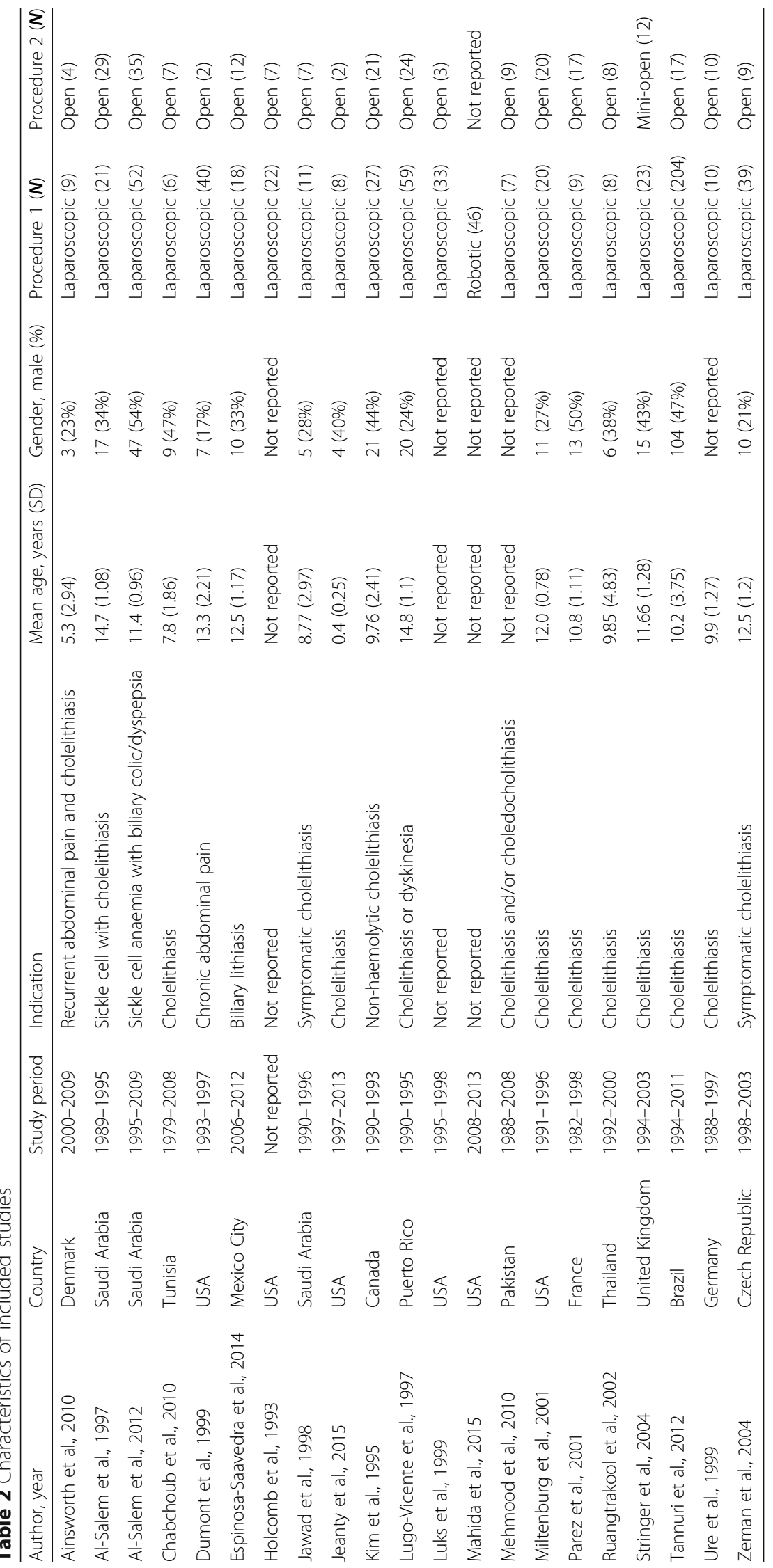




\begin{tabular}{|c|c|c|c|c|c|}
\hline Author, year & $\frac{\text { Laparoscopic }}{\text { Events / Total }}$ & $\frac{\text { Open }}{\text { Events / Total }}$ & Relative Risk (95\% CI) & RR (95\% Cl) & $\begin{array}{c}\text { Weight } \\
\text { (\%) }\end{array}$ \\
\hline Al-Salem, 1997 & $4 / 21$ & $6 / 29$ & & 0.92 (0.30 to 2.86$)$ & 19 \\
\hline Lugo-Vicente, 1997 & $12 / 59$ & $10 / 24$ & & 0.49 (0.24 to 0.98$)$ & 50 \\
\hline Miltenburg, 2001 & $1 / 20$ & $0 / 20$ & & 3.00 (0.13 to 69.52$)$ & 2 \\
\hline Parez, 2001 & $2 / 9$ & $1 / 17$ & & 3.78 (0.39 to 36.22$)$ & 5 \\
\hline Ruangtrakool, 2002 & $0 / 8$ & $2 / 8$ & & 0.20 (0.01 to 3.61$)$ & 3 \\
\hline Al-Salem, 2012 & $4 / 52$ & $8 / 35$ & & 0.34 (0.11 to 1.03$)$ & 19 \\
\hline Tannuri, 2012 & $2 / 204$ & $0 / 17$ & & $0.44(0.02$ to 8.80$)$ & 3 \\
\hline \multirow{3}{*}{ Pooled effect: $I^{2}=1 \%$} & & & & $0.57(0.35$ to 0.94$)$ & \\
\hline & & 0.01 & 0.1 & 100 & \\
\hline & \multicolumn{4}{|c|}{ Laparoscopic } & \\
\hline
\end{tabular}

complication rate and length of hospital stay when compared to open cholecystectomy, although had a longer operative time. There is limited evidence in relation to post-operative pain outcomes or the comparison between robotic-assisted versus laparoscopic or open cholecystectomy. Conversion rates between laparoscopic and open cholecystectomy varied between studies, with an overall conversion rate of $7 \%$.

\section{Strengths and weaknesses of the study}

To our knowledge, this is the first systematic review and meta-analysis to compare outcomes between surgical approaches for cholecystectomy in children and/ or adolescents. Some of the strengths of this review include the robust design and transparency, with a pre-specified research question and registered protocol as a priori in PROSPERO. In addition, we use a highly sensitive search strategy developed by an experienced librarian to identify studies comparing outcomes following cholecystectomy. Some of the limitations of this review include the limited number of studies found in the literature, especially on robotic-assisted cholecystectomy and the absence of randomised controlled trials. In addition, although all patients underwent cholecystectomy, the indications for surgery varied and included symptomatic cholelithiasis, choledocholithiasis or biliary dyskinesia which were often investigated in those with sickle cell anaemia, biliary dyspepsia or otherwise not specified. This may have introduced a level of heterogeneity within the investigated samples, and therefore, caution should be taken when interpreting the results. Furthermore, a subgroup analysis was not performed due to the small number of studies identified in the literature.

\section{Comparison with other studies}

No previous systematic review and meta-analysis focusing on childhood and/or adolescent cholecystectomy were identified $[5,32]$. Therefore, the results of this review were compared to systematic reviews and randomised controlled trials that included the adult population. None of the included studies reported any deaths following cholecystectomy. In the adult

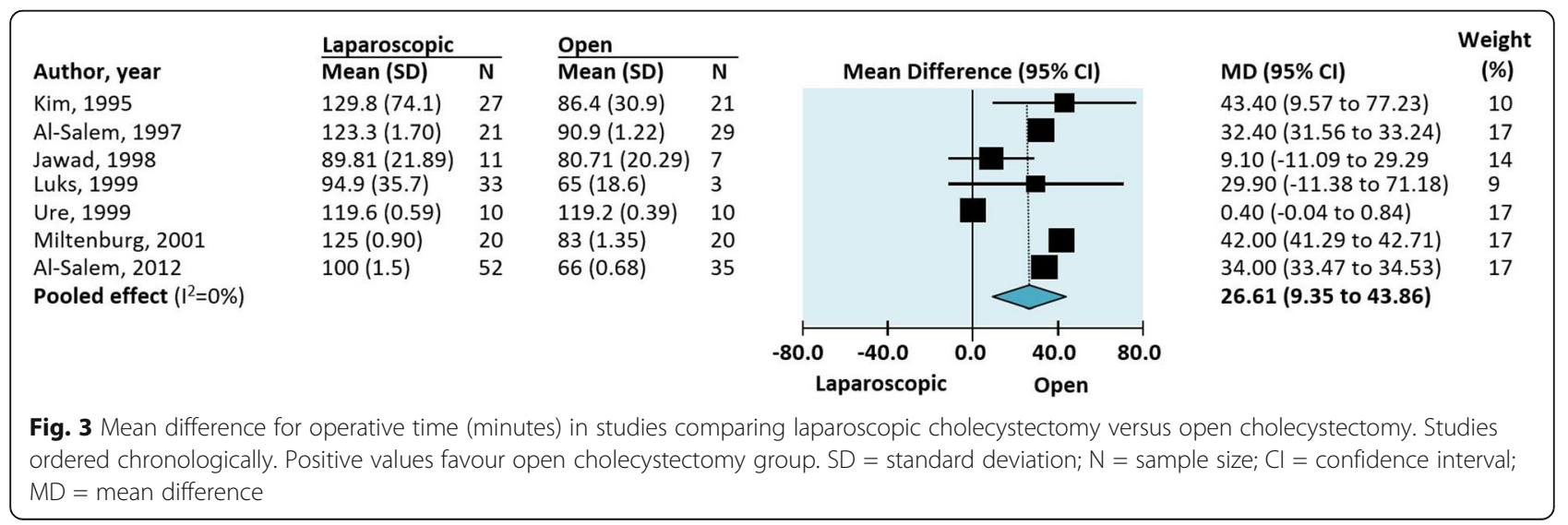




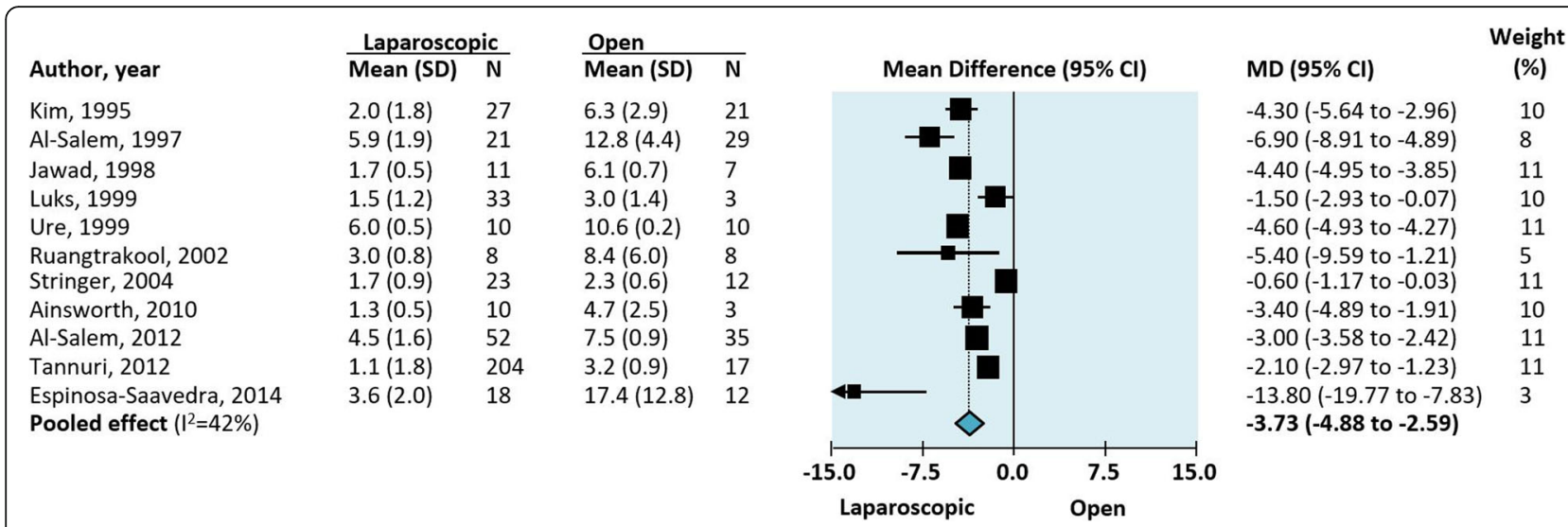

Fig. 4 Mean difference for the length of hospital stay (days) in studies comparing laparoscopic cholecystectomy versus open cholecystectomy. Studies ordered chronologically. Negative values favour laparoscopic cholecystectomy group. SD = standard deviation; $\mathrm{N}=$ sample size; $\mathrm{Cl}=$ confidence interval; $\mathrm{MD}=$ mean difference

population, the mortality rate is low, with no significant differences between open $(<1 \%)$ and laparoscopic procedures (0\%) [5]. Although our systematic review demonstrated a similar advantage to the adult population in terms of post-operative complication rates, where laparoscopy surgery was superior to open cholecystectomy, when a subgroup analysis in the adult population was performed including only high-quality trials, no significant differences were found between laparoscopic and open cholecystectomy [5]. Whether this same trend is observed in children and/or adolescents is currently unknown, due to the paucity of age-specific randomised controlled trials.

The operative time of laparoscopic surgery was longer when compared to open cholecystectomy (almost 30 min shorter in the open group). This may be explained by the initial of the learning curve to the laparoscopic approach and the additional time required to assemble the laparoscopic equipment during surgery. Most of the included studies had a small sample size (only $4 / 20$ presenting a sample $>50$ patients) with most samples presenting retrospective data extracted from medical records of large hospitals. Consequently, it is important to consider that a large number of surgeons would be performing a small number of surgeries, augmenting the effect of the initial learning curve on their operative time [33]. Whereas in the adult population, previous trials have demonstrated no difference in operative times between laparoscopic and open cholecystectomy possibly due to the higher frequency of cholecystectomies to improve the learning curve [32]. Another factor that could explain this difference between the young and adult population is that most high-quality trials (observed only in the adult population) required surgeons to be proficient in the procedure before they start delivering the intervention.
In our systematic review, our meta-analysis demonstrated that patients undergoing laparoscopic surgery have a significant shorter length of hospital stay when compared to an open procedure. It is well documented that minimally invasive surgical procedures result in shorter hospitalisation. Other studies that have investigated the effectiveness of laparoscopic versus open cholecystectomy have similar results, with a reduction in hospital duration by 3 days in patients that underwent laparoscopic cholecystectomy [5, 32].

Post-operative pain was only reported in two studies and was assessed based on the number of days patients required pain medication. This lack of evidence was also observed in systematic reviews in the adult population [5]. The mean reported conversion rate (laparoscopic to open cholecystectomy) in the current study was 7\% (range 0 to $25 \%$ ) and seems considerably lower when compared with the adult population where the conversion rate ranges from 10 to $36 \%$ [32].

\section{Meaning of the study and future directions}

Although this systematic review and meta-analysis found that laparoscopic cholecystectomy significantly reduces post-operative complication rates and length of hospital stay when compared to open cholecystectomy, the lack of high-quality randomised controlled trials prevent strong endorsement, and therefore, caution should be taken when interpreting these results. It is apparent that laparoscopic cholecystectomy is safe for the children and/or adolescent population, with no deaths reported and an acceptable post-operative complication and conversion rate. The fast uptake of robotic-assisted surgery, observed in other surgical specialities, must be embedded in clinical trials investigating the effectiveness over laparoscopic and open cholecystectomy. Furthermore, further studies should investigate if age would influence surgical outcomes and 
other patient-reported outcomes. Other variables, such as endoscopic retrograde cholangiopancreatography and their potential influence on the length of hospital stay, should also be investigated.

This systematic review and meta-analysis indicate that laparoscopic cholecystectomy is likely to reduce postoperative complication rates and length of hospital stay, despite a longer operative time compared to an open cholecystectomy. There limited evidence that laparoscopic cholecystectomy reduces pain when compared to open surgery. Whether minimally invasive surgery results in better surgical and patient-reported outcomes over open cholecystectomy is unknown due to the limited evidence to date.

\section{Abbreviations}

CENTRAL: Cochrane Central Register of Controlled Trials;

CMA: Comprehensive meta-analysis; MD: Mean difference; NOS: NewcastleOttawa Scale; PRISMA-P: Preferred Reporting Items for Systematic Review and Meta-Analysis Protocols; PROSPERO: International Prospective Register of Systematic Reviews; RCTs: Randomised controlled trials; RR: Relative risk

\section{Acknowledgements}

Not applicable.

\section{Authors' contributions}

DS and KW designed the study. KW, CT and DS collected data. DS and KW wrote the first draft of the manuscript. DS, KW, CT, DY, CS and AJ revised the first draft into the final manuscript. DS, KW, CT, DY, CS and AJ contributed to data analysis, interpretation of results and revision of the manuscript. The authors read and approved the final manuscript.

\section{Funding}

This research did not receive any specific grant from funding agencies in the public, commercial or not-for-profit sectors.

\section{Availability of data and materials}

All data generated or analysed during this study are included in this published article.

Ethics approval and consent to participate

Not applicable.

\section{Consent for publication}

Not applicable.

\section{Competing interests}

The authors declare that they have no competing interests.

\begin{abstract}
Author details
${ }^{1}$ Surgical Outcomes Research Centre (SOuRCe), PO Box M157 Missenden Road, Sydney, New South Wales 2050, Australia. ${ }^{2}$ Faculty of Medicine and Health, The University of Sydney, Central Clinical School, Sydney, New South Wales, Australia. ${ }^{3}$ Upper Gastrointestinal Department, Royal Prince Alfred Hospital, Sydney, New South Wales, Australia. ${ }^{4}$ RPA Institute of Academic Surgery (IAS), Royal Prince Alfred Hospital and University of Sydney, Sydney, New South Wales, Australia. ${ }^{5}$ Department of Paediatric Surgery, Sydney Children Hospital, Randwick, New South Wales, Australia.
\end{abstract}

Received: 23 March 2020 Accepted: 18 June 2020

Published online: 30 July 2020

\section{References}

1. Greer D, Heywood S, Croaker D, Gananadha S. Is 14 the new 40: trends in gallstone disease and cholecystectomy in Australian children. Pediatr Surg Int. 2018;34(8):845-9.
2. Poddighe DSV. Acute acalculous cholecystitis in children. World J Gastroenterol. 2018;24(43):4870-9.

3. Garey C, Laituri C, Ostlie D. St. Peter S. Single-incision laparoscopic surgery and the necessity for prospective evidence. J Laparoendosc Adv Surg Tech A. 2010;20(5):503-6.

4. Balaguer E, Price M, Burd R. National trends in the utilization of cholecystectomy in children. J Surg Res. 2006;134(1):68-73.

5. Keus F, de Jong J, Gooszen H, Laarhoven C. Laparoscopic versus open cholecystectomy for patients with symptomatic cholecystolithiasis. Cochrane Database of Systematic Reviews. 2006:1465-858.

6. Gurusamy K, Samraj K, Fusai G, Davidson B. Robot assistant versus human or another robot assistant in patients undergoing laparoscopic cholecystectomy. Cochrane Database of Systematic Reviews. 2012:1465-858

7. Antoniou S, Antoniou G, Koch O, Pointner R, Granderath F. Meta-analysis of laparoscopic vs open cholecystectomy in elderly patients. World J Gastroenterol. 2014;20(46):17626-34.

8. Shamseer L, Moher D, Clarke M, Ghersi D, Liberati A, Petticrew M, et al. Preferred Reporting Items for Systematic Review and Meta-Analysis Protocols (PRISMA-P) 2015: elaboration and explanation. BMJ : British Medical Journal. 2015;349:g7647.

9. Al-Salem AH, Issa H. Laparoscopic cholecystectomy in children with sickle cell anemia and the role of ERCP. Surg Laparosc Endosc Percutan Tech. 2012;22(2):139-42.

10. Al-Salem AH, Nourallah H. Sequential endoscopic/laparoscopic management of cholelithiasis and choledocholithiasis in children who have sickle cell disease. J Pediatr Surg. 1997;32(10):1432-5.

11. Al-Salem AH, Qaisaruddin S, Al-Abkari H, Nourallah H, Yassin YM, Varma KK. Laparoscopic versus open cholecystectomy in children. Pediatr Surg Int. 1997;12(8):587-90.

12. Alwabari A, Parida L, Al-Salem AH. Laparoscopic splenectomy and/or cholecystectomy for children with sickle cell disease. Pediatr Surg Int. 2009; 25(5):417-21.

13. Ainsworth AP, Axelsen AR, Rasmussen L. Cholecystectomy in children. Dan Med Bull. 2010;57(11):A4201.

14. Holcomb GW. Laparoscopic cholecystectomy. Semin Pediatr Surg. 1993;2(3): 159-67.

15. Chabchoub I, Bouraoui A, Maalej B, Aloulou H, Mahfoudh A, Kamoun T, et al. Cholelithiasis in children: a single centre experience. Arab Journal of Gastroenterology. 2010;11(4):215-8.

16. Dumont RC, Caniano DA, Chwals W, Gollin G. Hypokinetic gallbladder disease: a cause of chronic abdominal pain in children and adolescents. J Pediatr Surg. 1999;34(5):858-62.

17. Espinosa-Saavedra D, Flores-Calderon J, Gonzalez-Ortiz B, RodriguezGonzalez P. Characteristics of pediatric patients with biliary lithiasis. Immediate post-operative evolution. Rev. 2014;52 Suppl 2:S74-7.

18. Jawad AJ, Kurban K. el-Bakry A, al-Rabeeah A, Seraj M, Ammar A. Laparoscopic cholecystectomy for cholelithiasis during infancy and childhood: cost analysis and review of current indications. World J Surg. 1998;22(1):69-73 discussion 4.

19. Jeanty C, Derderian SC, Courtier J, Hirose S. Clinical management of infantile cholelithiasis. J Pediatr Surg. 2015;50(8):1289-92.

20. Kim PCW, Wesson D, Superina R, Filler R, Holcomb G. Laparoscopic cholecystectomy versus open cholecystectomy in children: which is better? J Pediatr Surg. 1995;30(7):971-3.

21. Lugo-Vicente HL. Trends in management of gallbladder disorders in children. Pediatr Surg Int. 1997;12(5-6):348-52.

22. Luks FI, Logan J, Breuer CK, Kurkchubasche AG, Wesselhoeft CW Jr, Tracy TF Jr. Cost-effectiveness of laparoscopy in children. Archives of Pediatrics and Adolescent Medicine. 1999;153(9):965-8.

23. Mahida JB, Cooper JN, Herz D, Diefenbach KA, Deans KJ, Minneci PC, et al. Utilization and costs associated with robotic surgery in children. J Surg Res. 2015;199(1):169-76.

24. Mehmood A, Khan MA. Biliary stones: an atypical cause of abdominal pain in paediatric age group. JPMA The Journal of the Pakistan Medical Association. 2010;60(12):1042-4.

25. Miltenburg DM, Schaffer IRL, Palit TK, Brandt ML. Laparoscopic cholecystectomy in children: is it better than open surgery? Pediatric Endosurgery and Innovative Techniques. 2001;5(1):13-7.

26. Parez N, Quinet B, Batut S, Grimprel E, Larroquet M, Audry G, et al. Cholelithiasis in sickle cell children: experience of a French pediatric hospital. [French]. Arch Pediatr. 2001;8(10):1045-9. 
27. Ruangtrakool R, Mungnirandr A, Laohapensang M, Sathornkich C. Laparoscopic cholecystectomy versus open cholecystectomy in children. J Med Assoc Thai. 2002;85(2):172-8.

28. Stringer MD. Informed consent and choice in cholecystectomy. Pediatr Surg Int. 2004;20(10):741-3.

29. Tannuri ACA, Leal AJG, Velhote MCP, Gonlcalves MEP, Tannuri U. Management of gallstone disease in children: a new protocol based on the experience of a single center. J Pediatr Surg. 2012;47(11):2033-8.

30. Ure BM, Lefering R, Holschneider AM. Cost analysis of laparoscopic cholecystectomy in children. Eur J Pediatr Surg. 1999;9(1):8-12.

31. Zeman L, Petru O, Rygl M, Keil R, Pycha K, Vyhnanek M, et al. Therapy of complicated cholelithiasis in children. [Czech]. Cesko-Slovenska Pediatrie. 2004;59(12):624-8.

32. Coccolini F, Catena F, Pisano M, Gheza F, Fagiuoli S, Di Saverio S, et al. Open versus laparoscopic cholecystectomy in acute cholecystitis. Systematic review and meta-analysis. Int J Surg. 2015;18:196-204.

33. Moore MJ, Bennett CL. The learning curve for laparoscopic cholecystectomy. The Southern Surgeons Club. Am J Surg. 1995;170(1):55-9.

\section{Publisher's Note}

Springer Nature remains neutral with regard to jurisdictional claims in published maps and institutional affiliations.

\section{Submit your manuscript to a SpringerOpen ${ }^{\circ}$ journal and benefit from:}

- Convenient online submission

- Rigorous peer review

- Open access: articles freely available online

- High visibility within the field

- Retaining the copyright to your article

Submit your next manuscript at $\boldsymbol{\nabla}$ springeropen.com 